\title{
Water, health and the body: the tide, undercurrent and surge of meanings
}

\author{
Nick W. Verouden · Frans J. Meijman
}

Received: 10 May 2010/Accepted: 14 May 2010/Published online: 1 June 2010

(C) The Author(s) 2010. This article is published with open access at Springerlink.com

\begin{abstract}
Water has meaning for health, illness and wellbeing. Central themes of meaning can be identified consistently throughout history, sometimes easily discernible, while at other times more difficult to identify. These meanings have a substantial social dimension, and reflect physical and bodily interactions with water. This article considers how these aspects of water have caused specific meanings of water to be prioritized by the medical world and the general public throughout history. It focuses on different medical and everyday settings such as traditional forms of medicine, therapeutic and curative practices in seaside sanatoria and spas, and public health initiatives. Different meanings of water can still be identified in contemporary health, where they are used to encapsulate and express an extraordinary range of experiences, meanings and values about health, illness and wellbeing. These meanings of water are related to the emergence of a new health consciousness in which responsibility for health has shifted from society to the individual. Water's meanings reflect tensions that arise from preventive health programs and the health industry, and provide avenues for expressing social identity for various groups within Western cultures.
\end{abstract}

Keywords Water $\cdot$ Meaning $\cdot$ Health $\cdot$ Body $\cdot$ Culture $\cdot$ Identity

\section{Introduction: water in the context of health, illness and wellbeing}

Throughout history the use of water has reflected various experiences and interpretations of and values about health, illness and wellbeing. The medical world and the general public have viewed water as harmful, beneficial or healthy. Presently, however, water is

N. W. Verouden $(\bowtie)$

Student Health Services, Department of Research, Development and Prevention, University of Amsterdam, Amsterdam, The Netherlands

e-mail: nverouden@hotmail.com

F. J. Meijman

Department of Metamedica/Medical Humanities, VU University Medical Centre, Amsterdam, The Netherlands 
conceived as something that the broader public considers essential to health and wellbeing. Various authors (Klepp 2009; Verouden 2007; Slyomovics 1993) have pointed to the proliferation of water in contemporary health fashions and its role in expressions of health, which are directed at improving the inside and outside of the body. A few examples include: spas that attract large numbers of people who visit to de-stress, pamper themselves or enhance their beauty; water therapies that improve overall wellbeing such as floatation, water massages, moisturising packs, water aerobics, water detoxification programs and water sound therapies. Homeopathic medicines and similar natural remedies are also undergoing a revival and water is important in less obvious everyday health practices. The bathroom is no longer a place of hygiene and the disposal of human waste, it now comes with comfortable bathtubs and multi-spray designer showers and has transformed into a place to unwind. People are increasingly drinking bottled mineral waters instead of high calorie sodas causing the bottled water industry to grow phenomenally over the last decade. Mineral waters now even outsell popular soft drinks like Coca Cola (Opel 1999).

Although the meanings of water in current health practices have not received much attention in contemporary scholarship, its non-health related meanings have been addressed extensively. Various authors indicate that water's meanings are continuously present throughout history and must be understood in relation to social, material and bodily processes (Tvedt and Oestigaard 2010; Strang 2004; Blatter et al. 2001). In nearly all societies water has a twofold meaning. On the one hand it represents notions such as purity, life, fertility and beauty; on the other hand it is mysterious, dangerous and capable of expressing chaotic and potentially dangerous experiences. Strang (2005) explains that water's dualistic meanings make it particularly useful for explaining and expressing broad and incongruous aspects of life. She notes that water imagery is widely used to 'describe the health of the human body, of social groups, of economic systems and of the environment ... it is the ultimate symbol of energy, potency, and the ability to extend human agency outwards into the world' (Strang 2005, pp. 110-111).

Water's dualistic meanings have been involved in different social processes influencing how people shape similarities and differences between themselves and others. Strang (2004) describes how the meanings attached to the river Stour provide residents of Dorset, England, with an idiom to express ideas about the community. They frame water as the 'essence of social being' and describe their communality and closeness by referring to it as a 'connective substance'. Other authors have instead focussed on how water is used to emphasise difference. Oestigaard (2006) describes how ritual practices of washing and bathing organize social differences in Indian society. Hindus use holy water to purify themselves, but this same water can pollute people in higher social classes. In a similar way, Anderson and Tabb (2002) illustrate how mineral waters represented social capital for eighteenth century aristocrats and the wealthy bourgeoisie, who used it to symbolize fashionableness and immoderation.

The meaning of water, however, is not limited to beliefs and ideas. A second theme in the literature focuses on the role of water's material aspects in the production of its meanings. This view indicates that the meaning of water is not a 'social extra' that can be understood apart from its diverse physical properties (Strang 2005). Water is a highly polymorphic substance and easily changes from a solid to a liquid state depending on factors such as temperature or whether it is a river, a lake or an ocean. Bachelard (1982) has pointed out that water's diverse material features reflect specific aesthetic and sensuous images in poetry, painting, and literature; clear waters inspire a reflective narcissism, deep waters reflect substance and profundity, flowing water is an ideal of purity, and the sea stands for violent and destructive forces as well as vitality and fecundity. Other authors 
have focussed on more mundane activities in which water's material aspects set boundaries for human endeavours to establish and organize society. Malpas (2006) indicates that the geographical borders drawn by major European rivers has greatly impacted the way national and local identities were shaped.

The third level on which water is meaningful, is the body. All human beings share the need for water to survive. They maintain their health by absorbing water from the outside and by excreting what is excessive into the outside world. Because water 'flows' between the outside world and the inner body, it can be used to transfer meanings and values from one frame of experience to another (Strang 2004). Analyses of water usage in and on the body have shown that these are essentially tied to broader social and cultural processes. Drinking water restores the physiological balance, but how one drinks can also reflect cultural attitudes and social behaviours (Vargas 2001). Similarly, how water is used to wash and bathe expresses cultural valuations of people's bodies (Twigg 1999). The excretion of water-in the form of bodily fluids - influences the way people think and feel about themselves and others. Urinating and spitting in public has been tied to notions of decency and are associated with understandings of the 'civilized body' (Elias 1978), while tears are explored as a medium for expressing inner-most feelings (Lutz 1999).

Summarizing: different health-related meanings of water can be continuously identified throughout history and are present in all cultures, in one form or another. Which meanings are given prominence in specific cultures at various times and how these have caused other meanings to move out of sight, is closely connected to social, material and biological processes. This article intends to analyse these aspects of water in relation to health, illness and wellbeing. Investigating water in relation to health makes it possible to understand the broader meanings of water in contemporary health practices. Examining various historical situations in which health and illness are associated with water, shows how the use of water in contemporary expressions of health, builds on earlier cultural meanings of water.

\section{The use of water in traditional forms of medicine}

First the role of water in the traditional medicine of numerous societies and cultures will be explored. Anthropologists mention the religious and magical significance of water in a wide range of cultural and historical contexts, pointing to its use in baptisms, ablutions, blessings, healing rituals, to counteract misfortunes, to expel evil forces, or as part of purification rituals or fertility rites (Kosso and Scott 2009; Ivanits 1989; Evans-Pritchard 1976, p. 135). In The Golden Bough, Frazer (1922, p. 577) described how Melanesians expelled demons and evil forces by means of ritual offerings like floating gifts on ocean waters or by dropping specially prepared foods into a deep well. More recent accounts mention uses of water in African healing practices, for example in diagnostic and divinatory practices or as part of purification rituals or fertility rites (Adogame 2000; Rinne 2001). Glass-Coffin (1998, p. 22) observed how traditional healers in Peru capture the evil spirit by sucking the disease from the victim's body and putting it in a special mixture consisting of water, tobacco, flowers and herbs, and then spit this mixture into a flowing river.

Although there is considerable cultural variation within these societies, and it is difficult to generalize, many of these practices establish a meaning of water as a 'life giving' substance that can purify and regenerate. Eliade (1993, p. 130) has explained that in many religious societies: 'The waters symbolize the universal sum of virtualities; they are fons et origo, "spring and origin", the reservoir of all possibilities of existence; they precede every 
form and support every creation'. Immersion in water is represented as the dissolution of forms, while contact is followed by regeneration and feelings of being reborn. Before water is considered to possess powers it is often treated in specific ways: through prayers, magic spells and rituals incantations, behavioural gestures, animal sacrifices, boiling, or adding herbs or other plants (Rinne 2001). Water's powers are also closely connected to the geographical origin of the place from where it derives (Thomas 1997). To increase the efficacy of water and transform it from an ordinary substance to a powerful one, it frequently has to be fetched from far-away springs, rivers, lakes or glaciers or has to be carried over considerable distances (Adogame 2000; Salnow 1987). The ritual preparation of water cannot be done by just anyone. Unleashing water's powers usually involves a 'series of consecrations and 'testings' (Eliade 1993, p. 193). Roberts (2000), for instance, describes the rituals of the boiling water oracle of the Tabwa, in the southeastern sector of the Democratic Republic of the Congo, in which the healer has to plunge his hands into a pot of roaring water in order to determine the underlying cause of the illness.

The significance of water in magical and religious uses is closely connected to beliefs and practices in which disease is conceptualized in holistic terms as an imbalance between the physical body and the social, cultural and natural universe. Healing involves restoring balance and is mediated by symbols and objects. Water's meaning as a 'life-giving' substance reflects this view of illness; its symbolic capacity to represent formlessness as well as regeneration and change is appropriated to describe and interpret concerns about the social body that underlie sickness and address anxieties that arise from these potentially disorderly experiences. Explaining this view of water, Bastien (1985, p. 156) describes the river as a dominant symbol in the healing ritual of a community of Indians living in the Bolivian Andes. The river signifies a transition point where everyday life concerns can be transcended and tensions underlying bodily sickness that form a danger to the social body, can be addressed and resolved.

The idea that water reflects a harmony between the physical, social and ecological environment can already be found in ancient medicine. Hippocratic medicine, for example, understood illness as the result of an imbalance in the body of the four humours (Schiefsky 2005). Hippocratic treatments were primarily intended to restore the imbalance in the bodily 'fluids' by addressing the living patterns of patients. Treatments included, among other things, mineral baths, steaming, the use of hot-water bottles, and alternating hot and cold water showers. Although there are considerable differences between the meaning of water in ancient medicine and the various religious and magical practices described, the continuity is striking; both are tightly bound to ideas of water as a health improving substance that restores the balance between physical and social systems.

\section{Early modern meanings of water and emerging healthy ways of life}

In the eighteenth century, there was a sharp rise in ideas that stressed water's health enhancing properties and promoted its actual application in medical circumstances, which added other meanings to the specific view of water as a source of life. In 1697, the physician John Floyer (1649-1734) published a ground-breaking work on the history of cold bathing in which he enthusiastically described the curative properties of water (Gibbs 1969). His ideas were embraced in the mid-eighteenth century by French and English physicians who widely agreed that cold water was beneficial for health. In this early modern period, in which all kinds of new and incongruous medical ideas were circulating, disease was still largely seen as the product of the dynamic inter-relationship of the 
individual organism with the environment. Many doctors emphasised the importance of restoring the harmony between nature and the body. Reworking old ideas, these doctors revived ancient beliefs of humors and bodily tension combining them with religious and mystical conceptualizations of water, which to a large extent, determined that water was perceived as a natural cure (Porter 1990, viii).

This period also saw the emergence of a set of ideas that stressed the advantages of healthy living, for instance, through vegetarianism and herbal treatments, which helped to shape the early notion of a healthy 'lifestyle' (Brandt and Rozin 1997). Therapies with water fitted perfectly into the context of the evolving health culture in this period. There was a revival of a multitude of water therapies, such as drinking water cures and the use of natural springs. However, this new sensitivity towards health was especially evident in the English and French upper classes' growing interest in the seaside and the curative properties of its waters.

Corbin (1994) has examined the growing attraction of the seaside and its waters by the eighteenth century's upper classes. In addition to the fashionable pastime these places offered, promenading and socializing with other influential quests, Corbin suggests that medical ideas played a pivotal role in the development of the seaside resorts. Physicians actively encouraged visitors to follow therapeutic regimes in order to 'steel' their bodies. Therapies such as drinking several glasses of seawater daily and ritualized confrontation with the crushing waves were added to the strict and regulated routines. From specially designed sea bathing carriages, visitors were plunged into ice-cold waters. This highly ritualized confrontation with the sea was held to enhance the bather's strength and vitality by restoring the balance between their body and nature.

Underlying the growing appeal of the seaside were broader cultural changes in the meaning of the sea, in which the negative image of the sea as a horrible and chaotic landscape that emanated 'unhealthy' vapours, was gradually replaced by a more positive view that emphasised its health enhancing properties power (Corbin 1994). The image of the sea as uncontrollable and as well as creative and generative is found in many cultures. Roman and Greek mythology present the sea as a source of fecund life. In the early modern period, the emergence of the concept of healthy life styles and new ways of caring for the body, again pushed this particular image of the sea into the foreground.

\section{Water as a curative agent}

The nineteenth century advances in medical knowledge about disease and the study of human physiology greatly influenced how water was perceived; thus we will discuss this period in more detail. These changes in the meaning of water were closely connected to its increasing role in the scientific treatment of disease. According to Blackbourn (2002, p. 10), this process caused 'a shift from the idea of water for health in the eighteenth century to taking the waters against sickness in the nineteenth'. Hydrotherapies were increasingly systematized and offered in specialized bathing hospitals and sanatoria, which became common throughout Europe. In these hospitals, doctors gained control over the venues through which water was distributed and applied. They based their empirical observations on scientific knowledge provided by chemists who classified mineral waters according to their curative properties (Hamlin 1990).

Weisz (2001) notes how French physicians, for example, distinguished more than 33 types of baths with various mineral constituents that were used for treating a wide range of diseases. In addition to the well-established bathing and drinking cures, physicians started 
to experiment with directing showers at specific body parts and orifices, wrapping patients in wet-sheet packs and making them inhale vapours. Some physicians even used subcutaneous injections of water and the injection of water into the rectum to stimulate the bowels (Goubert 1989, p. 137).

The idea that water had significant therapeutic powers because of what it contained, considerably reframed its meaning. Increasingly water's properties were understood in terms of what curative effects they had on the body (Prunskus 2006, p. 42). Compared to bathing in the sea (cures of the century before) where the therapies with water caused a feeling of enjoyment as much as discomfort, hydrotherapeutic cures in the nineteenth century were highly unpleasant experiences that demanded moral courage from patients. Within this framework, older ideas about water's powers became tied to medical ideas of bodily discipline and restraint. By using a variety of high-tech methods to treat the body with water, such as cage showers and mechanical sprays, spa doctors not only took control of water, they used their power over water as a symbol to emphasise and assert their control over the outside and inside of the body, thereby turning the 'active cure seeker of the eighteenth century' into 'a passive patient' (Blackbourn 2002, p. 10).

The perception of water as a symbol of discipline and order also found its way into the ideas and values of the middle class. Mackaman (1998) and Steward (2002), for instance, place the water cure in the broader context of evolving association between health issues and morality in this period. They describe the nineteenth century French and Austrian spas as places where middle-class social identities were shaped. Spas became a symbol of moral consciousness and middle class responsibility and had a prominent role in establishing more disciplined social behaviours. These notions were closely tied to beliefs and understanding about water. Water not only represented evidence of greater self-discipline and bodily restraint, but also mirrored the ideal of an orderly lifestyle that valued work and simple elegance over aristocratic excess and overindulgence.

\section{Water as a public symbol}

Due to the medical revolution at the end of the nineteenth century, belief in water's curative virtues became less popular in mainstream French and English medical circles. Even though some of the therapeutic properties of water could be scientifically demonstrated, no overall scientific explanation was found for its effectiveness (Weisz 2001). Hamlin (2000, p. 315) explains this paradigm shift in the perception of water in terms of a move from 'waters' to 'water', 'from a class of infinitely varied substances to a monolithic substance containing a greater or lesser concentration of adventitious ingredients, known as "impurities".' This cultural reformulation combines a 'variety of aqua's, eaus, waters and wassers' to a singular version of water (pp. 314, 321). Hamlin stresses that the emergence of this singular view of water should be understood against the background of the centralization of its control by mid-nineteenth century European-most notably English and French-health reformers. This involved two consecutive processes: on the one hand controlling the spread of water-borne diseases like cholera, typhoid and malaria by treating contaminated water and creating a publically available clean common drinking water supply on the other. Goubert (1989) has shown how this was linked to broader issues of national community building. The successes in water infrastructure during this period were seen as a great monument to social charity. Clean and easily accessible water was regarded a basic 'necessity' of life, indispensable for meeting national standards of health, justice, equality and responsibility. 
While clean drinking water represented ideals of a good and just society, health reformers attributed the opposing value of evil to unclean waters. This image of water was rooted in old symbolism and concepts linking water to ideas about danger and pollution. Douglas (1966) has made clear that concepts of dirt and pollution are used as analogies in nearly all societies for expressing essentially disorderly experiences and that beliefs about purification involve moral values through which order is restored. Health reformers in the nineteenth century attached an imagery of darkness, disease and death to the polluted waterways running through the major European cities. In England, for example, the waters of the Thames were represented as a monster soup, foul and stinking waters, through which all kinds of odious creatures swarmed (see Fig. 1). The production of this imagery contributed to the changing vision of water as a substance that possessed curative powers to that of a fluid that needed to be controlled and contained in the name of health. 'Pure' and 'good' water was no longer seen as something that was produced by 'Nature' but by 'Culture' (Strang 2004, p. 115). The process of separating water from nature was presented as a civil duty and echoed older moral values and desires about restoring the stability and order of society. Thus, health reformers expressed a new fear in an old idiom: control over water symbolized the connection between the health of the individual body and the health of wider society (see Fig. 2).

The re-shifting of water's meanings had significant consequences for the way it was managed. Hamlin notes that the development of this 'singular', 'secularized' and 'disenchanted' image of water accompanied the introduction of the idea that the public was 'irresponsible and indiscriminate with respect to water-willing to pour anything down their throat' and policy aimed at protecting the 'laymen' from water (Hamlin 2000, p. 315). People were increasingly cautioned to drink only clean water and encouraged to follow a set of circumscribed hygienic routines, which involved regularly washing the body with water. As a result, the 'practical' or utilitarian image of water became central to everyday care for the body. Behind notions of cleanliness and hygiene there are continuities in the meaning of water. These changing habits of washing and bathing the body with water

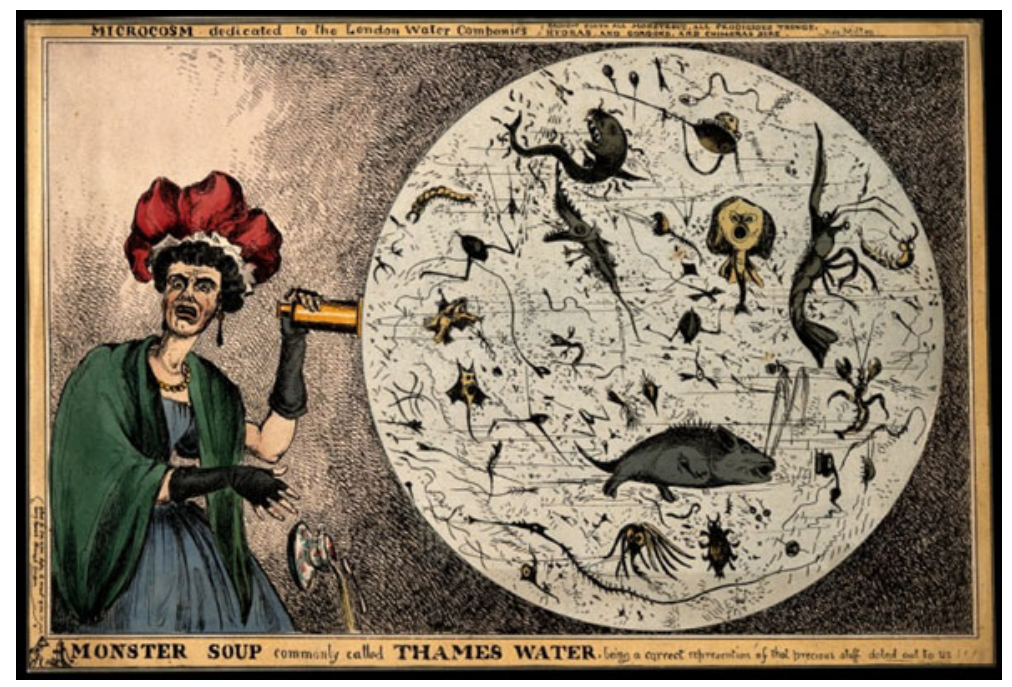

Fig. 1 Cartoon entitled monster soup showing how water is associated with darkness, disease and death (1828) 


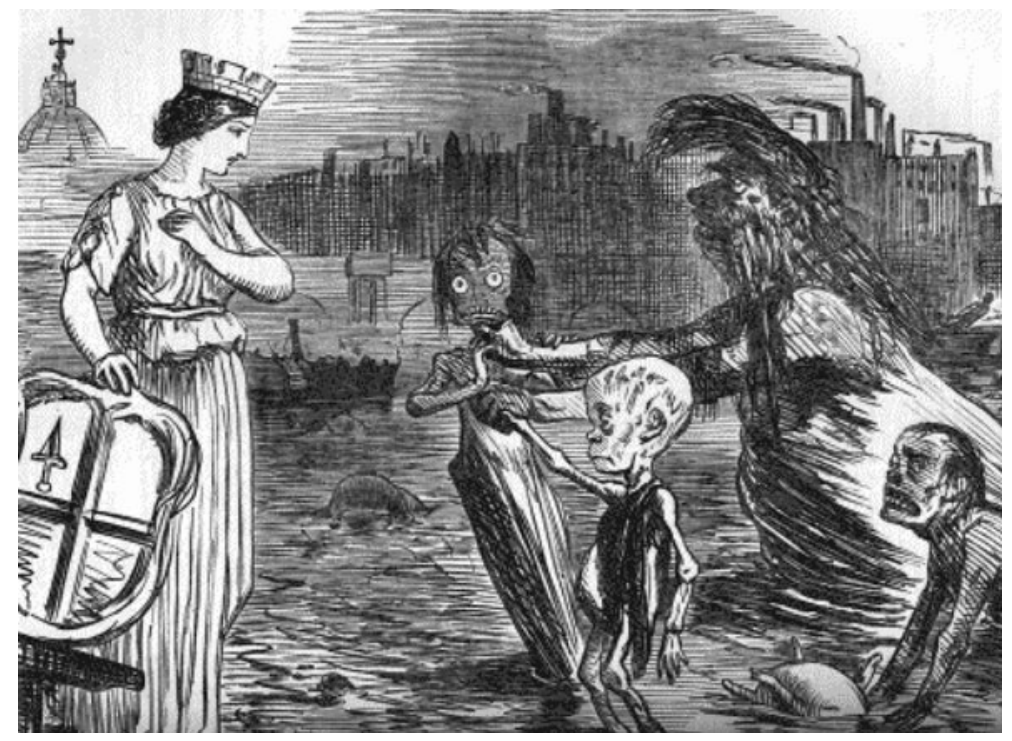

Fig. 2 Design for a fresco in the New Houses of Parliament showing how public health versus polluted water is represented in moral terms (1858)

reflected responsible and socially acceptable forms of daily domestic behaviour that demonstrated good manners and ideas about decency (Ashenburg 2007, p. 190).

Although this utilitarian image of water as a public good, essential to health, became more commonplace, local evaluations of water and health persisted outside the mainstream medical circles. The endurance of these practices led to continuous controversies over the meaning of water. Medical professionals vehemently denied the validity of miraculous cures occurring at places like the sanctuary of Lourdes and traditions of water practices that occurred throughout the nineteenth century, such as homeopathy (Harris 1999; Jütte et al. 1998), claiming they were the result of superstition and irrationality. While these new hygienic practices were thus prioritized, older meanings of water remained in the background.

\section{From water to $\mathrm{H}_{2} \mathrm{O}$}

The integration of water into residential, commercial, and industrial sectors in the second half of the twentieth century has continued to emphasise the 'practical' and utilitarian image of water, advancing the idea that the 'cultural' understanding of water has disappeared. This view can be found in the work ' $\mathrm{H}_{2} \mathrm{O}$ and the Waters of Forgetfulness' by Illich (1985), in which the late twentieth century understanding of water, as a chemical formula, $\mathrm{H}_{2} \mathrm{O}$, is presented as the outcome of more technically sophisticated methods of water delivery such as mechanical pumps and piped water. Developments in the field of architecture, technology and economics, among others, have framed water in material terms causing it to be valued predominantly for its functionality: cleaning purposes and waste disposal. Illich maintains that these developments have turned water into a substance that has lost all the social, cultural, and ecological values that constituted the historical 
relationship between humans and water: ${ }^{~} \mathrm{H}_{2} \mathrm{O}$ and water have become opposites: $\mathrm{H}_{2} \mathrm{O}$ is a social creation of modern times, a resource that is scarce and that calls for technical management' (pp. 75-76).

Illich's inquiry into the relationship between culture and water throughout the ages offers a linear and one-dimensional view in which water's meanings are seen as displacing each other over time. Examining the literature on the meaning of water, however, shows that while new dimensions have been added they did not radically alter contemporary understandings of water. As Goubert notes: 'Even though [water] has been secularized and made commonplace, this 'product' of the industrial revolution, because of its central place in nature and its relationship with our bodies, has retained its sacred character as it has infiltrated our customs, insinuated its way into our houses, bathed our inner depths and given rise to new rituals' (1989, p. 253).

The enduring significance of water is especially evident in current uses in health, illness and wellbeing. In mainstream medical circles an image of water as a material and functional substance also predominates. Water is valued for its cleaning and dissolving properties and its capacity to alleviate pain, swelling or cramps by transferring temperature, or to maintain fluid levels in the body. It is also essential for the effectiveness of health care; it is used for washing surgical tools and equipment and creating a germ-free environment for patients. These medical uses have incorporated older ways of thinking about and representing water. Macqueen (1995) observed how hand-washing practices of paediatric nurses are still strongly associated with ideas about pollution and danger. Nurses attributed different meanings to hand washing depending on contact with specific bodily fluid such as vomit or faeces. Before 'aseptic' procedures, they also surrounded hand washing with forms of ritual behaviour: 'After washing the hands they were held in exaggerated positions above the waist whilst walking from the sink to the 'sterile' area' (Macqueen 1995, p. 118). This example illustrates that water's significance has not vanished in medical situations. Even though the medical world values and prioritizes a utilitarian image of water, earlier beliefs have thus been incorporated into medical practices. Alongside this medical view, there is also a resurgence of older ways of thinking about and representing water in health in everyday settings. The medical utilitarian view of water is only one particular view, as more complex meanings now appear to exist alongside each other. The availability and accessibility of water have caused its multiple meanings to flow into everyday practices concerned with improving health, comfort, beauty and overall wellbeing. In the next paragraphs, the role of water in contemporary health fashions will be discussed.

\section{Water as a symbol of personal responsibility for health}

Health consciousness in western societies is characterized by an excessive fixation on good health. Crawford (1980, p. 368) has described how the responsibility for health has shifted to the individual. The concept of health has become synonymous with leading a responsible and balanced life and has come to stand for a model of citizenship. Health is linked to peoples' behaviours, intentions and interpretations and can be achieved through lifestyle choices. Crawford further notes that the pursuit of health reflects fundamental tensions and social conflicts. 'As a signifier of identities, moral capacities and social-emotionalphysical states of being, health becomes a discursive site for the articulation of conflicts and dilemmas that arise in the course of daily life' (Crawford 2006, p. 355).

The contemporary meaning of water must be understood against the background of these changes in the domain of health. The meanings of water condense and express an 
extraordinary range of experiences, interpretations and values about health and wellbeing in contemporary cultures. People prefer specific uses of water because they help them to imagine and express a variety of health ideals linked to the maintenance, strengthening or improvement of the health, beauty or wellbeing of body and mind. Which meanings are valued and highlighted depends on what one considers 'healthy' living; for example, people who value a healthy and balanced life may decide to unwind in a spa, while those who regard health as hygiene may simply wash themselves with water once a day. Conversely, one might believe that drinking energizing glacial waters, oxygenated, osmosized and de-ionized waters, or vitamin-enhanced bottled waters enhances energy, while soaking one's body in warm water in deluxe bathtubs promotes a feeling of overall wellbeing and happiness. These uses of water, in their own ways, mirror a notion of health that values will power, self-discipline and self-control (Blaxter 2004, p. 14). By using water, people explain and articulate their feelings and ideas about what constitutes an exemplary way of life and what it means to be a 'healthy' and responsible person.

The current attraction of bottled mineral water in societies where tapped water is highly potable may also be seen in this light. The vast use of bottled mineral waters in contemporary society is usually viewed as a consumer trend or as a symptom of a pervasive risk-adverse society such that bottlers are taking advantage of people's worries about the contamination of water supplies. However, the decision to drink bottled mineral water instead of tap water is also a 'healthy' and responsible choice-'Would you like coffee? No I'll take water'. The decision to consume expensive bottled mineral water may be seen as a symbolic expression of individual responsibility for health. Even though its health benefits are difficult to identify, and that mineral water is simply often bottled and marketed tap water, its use in everyday practices of drinking shows that people are taking charge of their health. This echoes older meanings of water that appeal to notions of bodily control and restraint.

The meaning of water in contemporary health activities does not only reflect health promotion messages that encourage people to practice self-control and moderation. People also use its meanings to distance themselves from or even resist health promotion messages or medical technologies. As a powerful symbol of naturalness and purity, water can be used to articulate health in ways that do not conform to dominant medical ideas about health; for example, water provides a natural alternative to surgical treatment, pills and health foods, as ads for the health benefits of water show (Fig. 3). Similarly, health activities with water can be used to resist dominant body images and medical intervention in one's body. Van Andel et al. (2008) found that many Dutch women of Surinamese descent regularly take herbal steam baths to enhance the appearance and health of their bodies, especially their vaginas. Based on traditional Surinamese religion, these women consider these steam baths as a natural alternative to chemical cosmetic products and in some cases even to so-called designer vaginal tightening operations.

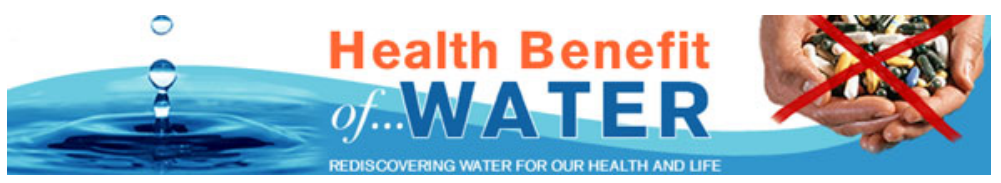

Fig. 3 Ad on website showing how water is presented as an alternative to pills (http://www.health-benefitof-water.com/health-benefit-of-water.html) 


\section{Water as image of lack of control, enjoyment and unbridled passion}

Water does not only reflect notions of bodily discipline and control over health. The commercialization of health and the increasing focus on health issues in a consumer culture have created a climate in which water is now also linked with various forms of pleasurable and transgressive behaviour. The predominant image of water promoted by the wellness industry appeals to all kinds of unconstrained pleasures, sensuous and sexual experiences and the desire to reunite with nature. Recent promotional campaigns for the world's largest bathing equipment manufacturer, Hans Grohe, clearly express this view; their showers entice consumers by offering a 'wellness treat', in which 'every drop is full of enjoyment'. The push to enjoy usually has a sexual undertone, which accentuates the unrestrained satisfaction that contact with water is supposed to provide (Fig. 4).

Discussing the contradictory nature of contemporary health experience, Crawford (2006) indicates that health promotion encourages people to take control over their health by being responsible and moderate, while consumer culture impels them towards release, indulgence and pleasure. The dualistic meaning of water as a means of both control and lack of control reflects this contemporary situation. In the face of pressure from the widespread

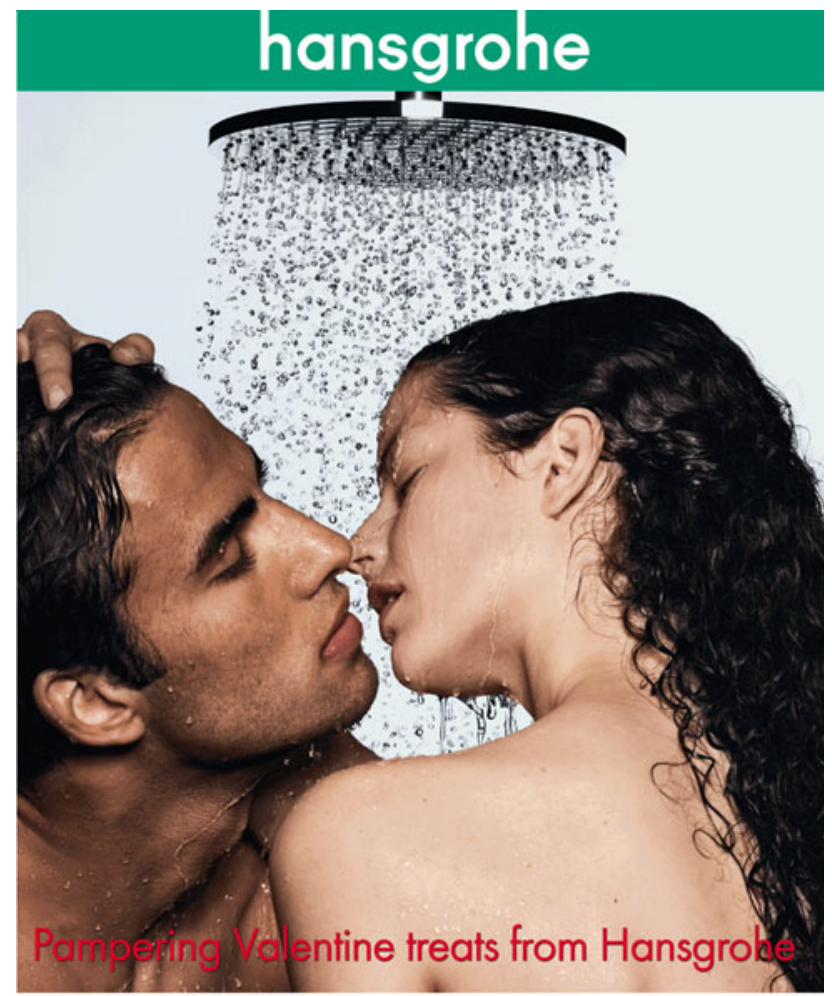

Pleasure your loved one this Valentine's Day with a wellness treat from Inahamani when you spend above $\$ 2000$ on Hansgrohe's products! *

"Promoson ends 28 feb 2009 . While vouchers las

Hansgrohe Pte Ltd • 69 Mohamed Sultan Road - Singapore 239015 • Tel: +65 68845060 - Fax: +6568845070 - Website: wmw.hansgrohe.com.sg • Email: info@hansgrohe.com.sg

Fig. 4 Ad for Hansgrohe showerheads showing how water is associated with erotic pleasure 
commercialization of health, water takes on renewed importance, signifying two opposing drives: one towards temperance and control, the other towards release and transgression of bodily discipline. The dualistic meanings of water help to articulate individual responsibility for health, and the pressures and constraints placed on people by preventive health programs, the health industry, and the media and may even resolve these tensions at times.

This double-sided aspect of water is found in various commercials for spas, in which water is said to provide a simultaneously healthy and pleasurable experience. The website of a popular Dutch spa states that its water therapies will restore balance and energy and offer untroubled and carefree pleasure. The use of water is said to give a feeling of enjoyment in a health conscious and responsible way providing a kind of 'light' enjoyment, without the fattening and unhealthy side effects of many other consumer goods and activities. Health activities with water offer what Williams (1998) has described as a form of 'ritualistic resolution', a process that balances the push and pull between socially established forms of bodily 'transgression' and discipline. In contemporary consumer culture, the meanings of water thus reflect the Apollonian drive for order, regularity, and self-control on the one hand, and the Dionysian impulse towards lack of discipline, unbridled passion, celebration of nature, and pleasure on the other.

\section{Water as source of social identity}

Social activities driven by the search for distinctive 'healthy' lifestyle and associated cultural tastes (Bourdieu 1984) have also highlighted the significance of water as an indicator of identity and social position. Individuals displaying and mobilizing social and bodily capital through water is hardly a recent idea; it was seen in Roman demonstrations of wealth through water. This process is now vastly enhanced by the accessibility and affordability of water. One just has to think of the enormous diversity of available waters and modes of consumption in contemporary consumer culture to get an idea of the scale on which former meanings of water are now available to people as lifestyle markers.

A few examples of how water provides a basis of social identity for various groups in society include: drinking water from the tap instead of a bottle or using it simply for hygienic purposes expresses plainness, soberness, and functionality all of which are symbolic meanings that can be used to express group membership in terms of pragmatic and sensible lifestyle options. This approach often includes hostility towards excessive uses of water. The use of water can also be used for cultivating the body's physical appearance. Using water to keep the body fit, slim and young may offer individuals a lifestyle choice based on a social identity that values elegance and 'good' taste, and often involves a considerable use of water. In more holistically oriented forms of health, dominant meanings of water are intertwined with holistic unity between bodily, social and psychological aspects of water and a respect for nature. These specific cultural preferences for water may be used to articulate a social identity based on a green, organic and natural lifestyle. This can for instance be seen in the popularity of sustainable and refillable Urban Canteen water bottles. In contrast, water may also be used to define a social identity based on prestige and social status. A recent trend in the world of bottled water is a bar that only serves bottled waters, for example, Bling $\mathrm{H}_{2} \mathrm{O}$, a luxury water that costs nearly 60 Euros. This group of consumers may see profligate water use as a demonstration of wealth and prosperity, and a way to define membership in a social group based on luxury and hedonism. The point here is that that the consumption of water for health, determined through various styles, fashions and especially the quantities consumed, 'generates the set 
of "choices" constituting lifestyles' (Bourdieu 1984, p. 171), and that it is through these choices that people's social positions are expressed and reaffirmed.

\section{Conclusion}

It can be concluded that investigating water through the lens of health enables us to understand the broader meanings of water in contemporary health practices. Some theorists (e.g., Illich 1985) have argued that the general attitude towards water has changed radically and that earlier cultural meanings are presently absent. This particular view can also be found in mainstream medical circles, where material qualities of water are prioritized over its symbolic powers. This article has instead shown that water is always heavily charged with meaning in relation to health, illness and wellbeing. Persistent themes of meaning can be identified consistently throughout history; sometimes these meanings are easily discernible, while at other times they are more difficult to identify as an undercurrent with hidden influences. However, considerable differences do exist in the way these meanings are shaped and expressed in various cultures and time periods. These differences depend on specific ways of thinking about health and the body, the processes by which health is made socially meaningful and associated with physical interactions with water.

The idea that water is beneficial to health is found in traditional medicine where it is widely considered a 'living thing' and is used to restore balance between physical and social systems. In seaside sanatoria and spas significant similarities with this restorative quality of water is apparent. Within this framework, water was increasingly perceived as a marker of distinctively healthy ways of living. The rise of public health movements in the nineteenth century separated 'water' from 'nature' and connected it to physiological definitions of health. This emphasised a 'practical' and utilitarian vision of water as $\mathrm{H}_{2} \mathrm{O}$. Below the surface, the meanings of water were connected to a new set of norms and social practices that reflected cultural notions about hygiene and cleanliness. Throughout the twentieth century, this image of water as a practical and functional substance has dominated mainstream medical thinking so that water is now primarily valued as a solvent and disinfectant. However, this culturally specific perception of water has not replaced other ideas about water, as various meanings of water co-exist in contemporary health practices resulting in its use in diverse health practices. These contemporary health-related meanings of water are closely connected to a health and body culture in which opposing drives of control and pleasure are balanced and provide avenues for expressing status, taste and distinction.

The study of water's meanings in relation to health offers valuable insights into the formation of its broader meanings in society and also raises significant issues about the way water is managed. This is the case because cultural attitudes about health determine which meanings are highlighted, thus greatly influencing people's decisions to use water. The current situation, in which water has become an important indicator of 'healthy' ways of living, is likely to lead to higher levels of water consumption. More historical and cultural information about the styles, fashions and meanings of water in health, can help us understand the cultural particularities of current activities in which enormous quantities of water are consumed. These insights may contribute to the development of better and more culturally sensitive methods to conserve water.

Open Access This article is distributed under the terms of the Creative Commons Attribution Noncommercial License which permits any noncommercial use, distribution, and reproduction in any medium, provided the original author(s) and source are credited. 


\section{References}

Adogame A (2000) Doing things with water: water as a symbol of life and power in the Celestial Church of Christ. Stud World Christ 6(1):59-77

Anderson SC, Tabb BH (2002) Water, leisure and culture: European historical perspectives. Berg Publishers, Oxford

Ashenburg K (2007) The dirt on clean. An unsanitized history. North Point Press, New York

Bachelard G (1982) Water and dreams: an essay on the imagination of matter. The Pegasus Foundation, Dallas

Bastien JW (1985) Mountain of the condor: metaphor and ritual in an Andean aylla. Waveland Press, Prospect Heights

Blackbourn D (2002) Fashionable spa towns in nineteenth-century Europe. In: Anderson SC, Tabb BH (eds) Water, leisure and culture: European historical perspectives. Berg Publishers, Oxford, pp 9-22

Blatter J, Ingram H, Levesque SL (2001) Expanding perspectives on transboundary water. In: Blatter J, Ingram $\mathrm{H}$ (eds) Reflections of water. The MIT Press, Cambridge, pp 31-53

Blaxter M (2004) Health. Polity Press, Cambridge

Bourdieu P (1984) Distinction: a social critique of judgment and taste. Routledge, London

Brandt AM, Rozin P (eds) (1997) Morality and health. Routledge, New York

Corbin A (1994) The lure of the sea: the discovery of the seaside in the western world 1750-1840. Polity Press, Cambridge

Crawford R (1980) Healthism and the medicalization of everyday life. Int J Health Serv 10:365-388

Crawford R (2006) Health as meaningful social practice. Health 10:401-420

Douglas M (1966) Purity and danger: an analysis of concept of pollution and taboo. Routledge, London

Eliade M (1993) Patterns in comparative religion. New American Library, Inc, New York

Elias N (1978) The civilizing process, vol. I. The history of manners. Blackwell, Oxford

Evans-Pritchard EE (1976) Witchcraft, oracles, and magic among the Azande. Oxford University Press, Oxford

Frazer J (1922) The golden bough: a study in magic and religion. Oxford University Press, Oxford

Gibbs DD (1969) Sir John Floyer, MD (1649-1734). Br Med J 1:242-245

Glass-Coffin B (1998) The gift of life: female spirituality and healing in Northern Peru. University of New Mexico Press, Albuquerque

Goubert JP (1989) The conquest of water: the advent of health in the industrial age. Princeton University Press, Princeton

Hamlin C (1990) A science of impurity: water analysis in nineteenth century Britain. University of California Press, Berkeley

Hamlin C (2000) "Waters" or "water"? Master narratives in water history and their implications for contemporary water policy. Water Policy 2:313-325

Harris R (1999) Lourdes: body and spirit in the secular age. Viking, New York

Illich I (1985) H2O and the water of forgetfulness. The Dallas Institute of Humanities and Culture, Dallas Ivanits LJ (1989) Russian folk belief. M.E. Sharpe, Armonk

Jütte R, Risse GB, Woodward J (eds) (1998) Culture, knowledge, and healing: historical perspectives of homeopathic medicine in Europe and North America. European Association for the History of Medicine and Health, Sheffield

Klepp IG (2009) Does beauty come from within? Beauty and well-being in Norwegian spas. Medische Antropologie 21(1):39-51

Kosso C, Scott A (eds) (2009) The nature and function of water, baths, bathing, and hygiene from antiquity through the Renaissance. "Technology and change in history", vol 11. Brill Publishers, Leiden

Lutz T (1999) Crying: the natural and cultural history of tears. Norton, New York

Mackaman DP (1998) Leisure settings: bourgeois culture, medicine, and the spa in modern France. University of Chicago Press, Chicago

Macqueen S (1995) Anthropology and germ theory. J Hosp Infect 30(Supplement):116-126

Malpas J (2006) The forms of water: in the land and in the soul. Transform Cult eJ 1(2). http://epress.lib.uts.edu.au/journals/TfC

Oestigaard T (2006) Heavens, havens and hells of water: life and death in society and religion. In: Leybourne M, Gaynor A (eds) Water: histories, culture, ecologies. University of Western Australia, Perth

Opel A (1999) Constructing purity: bottled water and the commodification of nature. J Am Cult 22(4):67-77

Porter R (ed) (1990) The medical history of waters and spas: introduction. Wellcome Institute for the History of Medicine, London 
Prunskus L (2006) The last resort: spa therapy and the docile body in Victorian St. Catharines. Masters thesis, Brock University

Rinne E (2001) Water and healing: experiences from the traditional healers of Ile-Ife, Nigeria. Nordic J Afr Stud 10(1):41-65

Roberts AF (2000) Difficult decisions, perilous acts: producing potent histories with the Tabwa boilingwater oracle. In: Pemberton J (ed) Art and divination in Central and West Africa: a cross-cultural study. Smithsonian Institution Press, Washington, DC

Salnow MJ (1987) Pilgrims of the Andes: regional cults in Cusco. Smithsonian Institution Press, Washington, DC

Schiefsky MJ (Translator) (2005) Hippocrates on Ancient Medicine. Brill Academic Publishing, Leiden

Slyomovics S (1993) The body in water: Woman in American spa culture. In: Young K (ed) Bodylore. Tennessee University Press, Knoxville

Steward J (2002) The culture of the water cure in nineteenth-century Austria, 1800-1914. In: Anderson SC, Tabb BH (eds) Water, leisure and culture: European historical perspectives. Berg Publishers, Oxford, pp 23-36

Strang V (2004) The meaning of water. Berg Publishers, Oxford

Strang V (2005) Common senses: water, sensory experience and the generation of meaning. J Mater Cult 10(1):92-120

Thomas P (1997) The water that blesses, the river that flows: the place and the ritual imagination among the Temanambondro of Southeast Madagascar. In: Fox JJ (ed) The poetic power of place: comparative perspectives on Austronesian ideas of locality. Australian National University, Canberra, pp 23-42

Tvedt T, Oestigaard TA (2010) History of ideas of water: deconstructing nature and constructing society. In: Tvedt T, Oestigaard T (eds) A history of water. Series 2, vol 1. The ideas of water from antiquity to modern times. I.B. Tauris, London, pp 1-36

Twigg J (1999) The spatial ordering of care: public and private in bathing support at home. Sociol Health Illn 21(4):381-400

Van Andel T, Ruysschaert S, Behari-Ramdas J, Niekoop L, De Korte S, Koopmans D (2008) Het gebruik van genitale stoombaden door Surinaamse vrouwen (The use of genital steambaths by Surinamese women). Nederlands Tijdschrift voor Obstetrie Gynaecologie 121:242-246

Vargas LA (2001) Thirst and drinking as bio-cultural processes. In: de Garine I, de Garine V (eds) Drinking: anthropological approaches. Berghahn Books, New York, pp 11-21

Verouden NW (2007) Bevangen door water: waterverhalen in een medische context [Stories about water in medical situations]. In: Boot C, Meijman FJ, Vonk P (eds) Water: als medicijn! [Water as medicine]. Veen Magazines, Diemen

Weisz G (2001) Spas, mineral waters, and hydrological science in twentieth-century France. Isis 92:451-483

Williams SJ (1998) Health as moral performance: ritual, transgression and taboo. Health 2(4):435-445 